\title{
Research on the Importance of Regional Culture in the Character Creation of Oil Painting
}

\author{
Xueyan Ma \\ Ningxia Normal University, Arts Academy, Ningxia, China, 750000
}

Keywords: Regional Culture; Oil Painting Character Creation; Importance

\begin{abstract}
In the process of painting people, regional culture has an important influence on the creation of oil painting characters. For example, the impact on the creative theme, the impact on the creative style and so on. This paper mainly discusses the importance of regional culture in the creation of oil painting characters from the influence of regional culture in the creation of oil painting figures.
\end{abstract}

\section{The Connotation of Regional Culture}

The so-called regional culture mainly refers to the specific geographical scope of the formation of a typical, stable culture, but with the times continue to advance, regional culture is also constantly changing. Regional culture as a part of the cultural system, it is unique, contains a regional residents of the food culture, living culture, folk culture and so on. The difference between geographical environment and natural conditions is an important reason for the emergence of regional cultural differences. Different regions create people's different character characteristics, but also produced a different culture.

\section{The Regional Characteristics of Oil Painting Characters Creation}

This feature is mainly manifested in two aspects, one is the geographical features of the region, on the other hand is the cultural characteristic of the region.

\subsection{Geographical Characteristics}

Geographical features mainly refer to the local characteristics of the geographical environment on the creation of oil painting has the impact. For example, Chinese northern region more plains, the southern region more hills. The eastern part of the mountainous areas is the western region of the plateau. It is precisely because of this difference in geographical environment so that oil painting in the process of creation which incorporates more geographical features. China has a rich and colorful natural landscape, whether it is tropical or temperate continental climate, oil painting for the creation of a wealth of material. For example, some of Chinese oil painters to the western mountains and geomorphology as the background of Tibetan oil painting characters, the emergence of a lot of representative oil paintings.

\subsection{Cultural Regional Characteristics}

In the process of painting the characters, the unique culture of the region also makes the oil painting characters have the corresponding cultural characteristics. For example, in our country, different ethnic minority areas have their own national culture, in the minority figures as the object of oil painting creation and it will integrate more cultural connotations of ethnic minorities. From the macro point of view, the Chinese culture is also a typical regional culture, Chinese oil painting and Western oil painting is the biggest difference between the cultural connotations of the difference. Chinese oil painting contains the open, inclusive, the love of nature, the pursuit of harmony and all reflect the typical cultural characteristics of the region. 


\section{The Influence of Regional Culture on the Creation of Oil Painting Characters}

In the process of painting the characters, the scene of the regional culture and the form of the surface is the main reason for its influence, but also contains the cultural connotation behind the form, and the creation of the theme, creative style and creative emotion on the creation of oil painting characters is bigger.

\subsection{The Impact of Creative Themes}

The creation of the subject matter can be understood as the direction of creation, in the process of painting the creation of people, different regional culture will have different effects on the subject matter. For example, in the last century 80 's, the famous artist Luo Zhongli created the native theme of the oil painting figures. These oil paintings are workers, peasants, intellectuals, although the occupation is different, but they all highlight the regional cultural characteristics. Chen Danqing is also through the "Tibetan group painting" show of the Tibetan culture as the background of the Tibetan people's normal life. Therefore, from this point of view, the regional culture for the creation of oil painting characters has an important impact. On the one hand, the regional culture affects the characteristics of oil painting characters and China has 56 ethnic groups, living in every corner of the motherland, different customs and culture of different people's character. Through the creation of oil painting characters, you can see from the works of the cultural connotation behind the characters. On the other hand, the regional culture has an impact on the characters of the oil painting characters. For example, in the northern region of China, Mongolian and Tibetan are mainly nomadic life, so they will contain more desert feelings. Chinese southern Yi, Dai, mostly living in the beautiful mountains and rivers, as the theme of the oil painting character creation will be a lot more beautiful beauty.

\subsection{The Impact of Creative Style}

Oil painting is a lot of personal color, different oil painters because of the different understanding of oil painting art, will form their own different styles. In addition to being influenced by the subjective thinking of the creator, the style of painting is related to the regional culture chosen by the creator. In different regional cultures, the creator will inspire from the culture, produce and form a different creative style. For example, Liu Xiaodong's oil painting works to fully integrate the creative style of the Beijing culture, in Wang's works fully embodies the black land culture style, as well as Li Lajun oil paintings in the deep northern Shaanxi culture style, through these Eclectic cultural style, both to promote the painting of the creation of the diversity of people also shows the regional culture on the oil painting character creation style.

\subsection{The Influence of Emotion}

The influence of regional culture on the creation of oil painting characters is not only reflected in the subject matter, but also in emotion. Some scholars have pointed out that art is a silent language. Oil painting through the description of the characters in the picture to express the author's inner emotional changes, for example, the painting produced by the guest of the "Volga River Fu", full of the author's deep sympathy for the working people. The image of the labor modeled in this painting is, in the strict sense, not only the embodiment of the regional culture, but the description of the whole social background at that time. Similarly, in the Chinese oil paintings, "founding ceremony" as the theme of large oil paintings filled with strong patriotic feelings. This patriotic emotion is not only the embodiment of regional culture, but also a social culture, the embodiment of the era of culture.

In short, the regional culture of oil painting characters have an important impact, it affects the subject matter, affecting the creative style, but also affect the creative feelings. This is an important revelation for our future oil painting creation, especially oil painting characters.

\section{The Role of Regional Culture in the Creation of Oil Painting Characters}

In the above, this paper explores the influence of regional culture on the creation of oil painting 
characters. From a certain point of view, this influence is also the embodiment of regional culture to the creation of oil painting characters. Specifically, the regional culture in the oil painting character creation mainly plays the following three aspects of the role.

\subsection{Restore the Real Scene}

Oil painting creation, whether in the background of people, or in the background of natural landscape, is an expression of the art of life. It should be noted that in the creation of oil paintings, the authenticity of the scene has a higher demand. How to effectively achieve the authenticity of the scene need is to use regional culture to create. For example, Luo Zhongli in the process of painting the creation of the characters, through the restoration and expression of real life scenes, created a series of Sichuan farmers as the object of oil painting works. Through the real reproduction of the farmer's life scene in northern Shaanxi, Li Lijun created a large number of oil painting characters with the main contents of the peasants' life in northern Shaanxi. Jin Shangyi is the Tajik bride as the main oil painting characters' creation object, showing the Tajik people have a unique marriage culture. From these representative works can be seen, the regional culture helps to restore the real scene, through the painter lifelike picture performance, so that viewers have an immersive feeling.

\subsection{Record People's Feelings}

As the painter in the performance of the regional culture of oil painting characters with a certain emotional, or sympathy, or attachment, or joy, or feelings of sorrow ... ... or broad, or deep, or gentle, in short, the work will always be filled with a certain feeling. This feeling is in the creation of oil paintings through the geographical environment, natural landscape, clothing, props, characters, expressions, actions, etc., so that the regional culture in the oil painting character creation of another major role is to record people's feelings The For example, the Daqing oil workers to carry out the theme of oil painting characters, fully demonstrated when the oil workers to extract the first piece of oil field in China when the mood and emotional changes presented. Oil painter Wang Yidong on his hometown Yimeng Mountain has a deep feeling, hometown of local customs and natural style is the theme of his painting. For example, his work "home book" in the bride received a letter from the joy of home, works "Yimeng baby" little girl's simple and lovely and slightly timid expression, etc., are described in the region to create the region The unique cultural scene, but also recorded the feelings of people at that time.

\subsection{Express Self Emotion}

The oil painter expresses his own emotions through his own oil paintings. This expression is accompanied by a personal subjective color, in a sense also contains the characteristics of regional culture. It can be said that any excellent oil painting works not only in oil painting techniques have refined performance, but also in the emotional expression has a lot of moving place. Emotion is tension, through the oil painting works to express the feelings of the creator, both the charm of oil painting is also the foothold of oil painting. In the process of expression of self-emotion, oil painters from the regional culture to draw inspiration and nutrition, showing the author's love of life, the pursuit of art and the universal value of the feelings. Excellent oil painting works, with the power of moving people, every good oil painter should also have a regional culture given by the human feelings. In short, in the oil painting character creation, the regional culture plays an important role. Whether it is the restoration of the real scene, or the people feel the record, or the expression of the creator's own emotions, are fully demonstrated in the oil painting character creation process, to be rooted in the local culture of the soil, constantly Enrich the cultural connotation of oil painting characters. So that oil painting works more rich texture and tension.

\section{The Regional Culture Has Important Significance in the Entire Oil Painting Character Creation Process}

First of all, it is the emotional source of oil painting characters. China is a vast country, different regions showing different cultural characteristics. These cultural characteristics of the entire oil 
painting creation, especially the oil painting characters to give more people connotation, to the majority of oil painters to provide an important creative inspiration and material source. For example, China is now a variety of oil painting groups, there are Shandong painting schools, Xinjiang painting school and they are from their respective regional culture to get the corresponding oil painting characters inspiration. It is this regional culture that helps more oil painting creators go further on the road to oil painting.

Second, the regional culture is the main source of innovation in oil painting. In the process of painting the characters, not falling, unique style is a lot of oil painting creators of the main pursuit. From the perspective of modern art aesthetic point of view, innovation is eclectic is a kind of artistic innovation performance, innovation is not the artist's mind flash, but in a large number of oil painting practice process of continuous accumulation of creative experience. The creation of oil painting cannot be separated from the environment. Regional culture, as an important factor in the environment, provides an important reference for the innovation of oil painting characters in terms of material aspects, style and emotional expression. Therefore, from this point of view, regional culture is the main source of oil painting creative innovation.

Finally, the regional culture is the oil painting character creation inheritance and development of the important foothold. The value of oil painting art is not just the oil painting itself and it is more of a cultural manifestation and expression. Although the oil painting is a form of Western painting, but after hundreds of years in China, Chinese oil painting creation has a richer cultural heritage. Which, including the regional cultural heritage, at present, China is promoting the protection of intangible culture, some representative of the minority culture is an important object of protection, through the continuous inheritance of oil painting and development, in some form Is also conducive to the development of Chinese regional culture. Therefore, from this point of view, the regional culture is the oil painting character creation inherited the traditional foothold.

\section{Conclusion}

The value of regional culture in the creation of the whole oil painting characters is constantly highlighting how to better explore the organic combination of regional culture and oil painting characters, and will also be the main direction of the future oil painting characters creation.

\section{Acknowledgements}

Fund Project: This paper is 2017 Ningxia Normal University Scientific Research Project Fund funded Project No: NXSFZD1702

\section{References}

[1] Ren Yan. On the regional characteristics of Chinese oil painting - Zeng Hao "flying" of the regional analysis[J]. Literature and Art Life · Zhong Zhong, 2017 (1)

[2] Yan Liqun. On the Xiangxi regional culture on Shen Congwen's novel "Border Town" creation influence [J]. Young writers, 2017 (6)

[3] Zhang Mingyang. On the practice of local culture in teaching Chinese as a foreign language Taking Luzhou as an example[J]. Chinese character culture, 2017 (9)

[4] Xie Yongqi. On the practice of "composite material" in Xinjiang oil painting creation [J]. Popular Literature, 2017 (14)

[5] Huang Kun. On the modern Chinese landscape oil painting language and tactics of the evolution[J]. Art Education Research, 2017 (9). 